\section{P203 SEXUAL RISK BEHAVIOUR AND STI TESTING BEHAVIOUR OF MALE SEX WORKERS WHO HAVE SEX WITH MEN (M\$M) IN THE NETHERLANDS}

${ }^{1,2} \mathrm{C}$ Peters ${ }^{*},{ }^{1,3} \mathrm{~N}$ Dukers-Muijrers, ${ }^{1,2} \mathrm{Y}$ Evers, ${ }^{1,2} \mathrm{C}$ Hoebe. ${ }^{1}$ Department of Social Medicine, Care and Public Health Research Institute (CAPHRI), Maastricht University/Maastricht UMC +, Maastricht, The Netherlands; ${ }^{2}$ Department of Sexual Health, Infectious Diseases and Environmental Health, South Limburg Public Health Service (GGD Zuid Limburg), Heerlen, The Netherlands; ${ }^{3}$ Department of Health Promotion, Care and Public Health Research Institute (CAPHRI), Maastricht University/Maastricht UMC+, Maastricht, The Netherlands

10.1136/sextrans-2021-sti.292

Background Male sex workers who have sex with men (M $\$ \mathrm{M})$ are a high-risk group for acquiring sexually transmitted infections (STI) including human immunodeficiency virus (HIV).

An understanding of sexual risk behavior is necessary to successfully develop risk-reduction strategies. However, limited scientific knowledge is available on sexual risk behaviour of $\mathrm{M} \$ \mathrm{M}$ in the Netherlands.

The aim of this study was to assess M\$M's sexual risk behaviour in the Netherlands, e.g. STI testing behaviour, condom use, drug use before/during sex and hepatitis B (HBV) vaccination.

Methods For this qualitative study semi-structured individual in-depth interviews were conducted with $20 \mathrm{M} \$ \mathrm{M}$ who worked home-based in the Dutch province of Limburg. Respondents were recruited by convenience sampling until saturation was reached via 1) five websites and smartphone applications commonly used by M\$M 2) STI clinic 3) two gay sauna's. An interview guide was developed including themes such as sexual health, condom use and STI testing behaviour. The interviews' recordings were transcribed verbatim and inductively coded with Atlas.ti 8 .

Results The majority of the interviewed M\$M would regularly get tested for STI, however some had never or irregularly been tested. Their STI risk perception often determined testing behaviour. Condom use was reported to be high with anal sex, but low with oral sex. Condom use was mostly determined by STI risk perception, trust in clients and sexual pleasure. A third of the respondents was not vaccinated against $\mathrm{HBV}$, mainly due to the lack of information and awareness of $\mathrm{HBV}$ vaccination and low risk perception of HBV.

Furthermore, almost half of the M\$M had used drugs before/during sex in the past six months.

Conclusion In this study we were able to assess sexual risk behaviour of $20 \mathrm{M} \$ \mathrm{M}$ in the Netherlands. The results can be taken into account for the tailoring of future risk-reduction strategies for M\$M.

\section{P204 COMPARISON OF TIME TO SYPHILIS TREATMENT SUCCESS COMPARING PATIENTS WITH REPEAT VERSUS DE NOVO INFECTION}

\footnotetext{
${ }^{1,2} \mathrm{~K}$ Konda* ${ }^{2} \mathrm{~S}$ Vargas, ${ }^{2} \mathrm{G}$ Calvo, ${ }^{2} \mathrm{E}$ Reyes, ${ }^{3} \mathrm{~L}$ Giancani, ${ }^{2} \mathrm{C}$ Caceres, ${ }^{1} \mathrm{~J}$ Klausner. ${ }^{1}$ University of California, Los Angeles, Los Angeles, USA; ${ }^{2}$ Universidad Peruana Cayetano Heredia, Lima, Peru; ${ }^{3}$ University of Washington, Seatle, USA
}

\subsection{6/sextrans-2021-sti.293}

Background During syphilis infection, RPR titers are used to assess response to treatment with a 4-fold titer decrease indicating treatment success. To improve understanding of how RPR titers vary after treatment can help improve syphilis care, we evaluated the time to a 4-fold decrease in RPR titer from diagnosis with active syphilis comparing those with repeat and de novo syphilis infection.

Methods We determined the RPR titers of patients at least 1-month post-diagnosis with active syphilis comparing patients with documented prior syphilis versus those with documented de novo syphilis (syphilis-naïve), these individuals had a negative syphilis rapid test within one year of the current infection. All individuals received appropriate treatment at enrollment. Fisher's exact tests were used to compare the repeat-infection and syphilis-naïve groups and multivariate Cox regression was conducted to explore time to 4-fold titer reduction, adjusting for baseline titer and HIV status.

Results Among the 106 individuals enrolled with at least one post-baseline visit, by 1 -month $45 \%$ of individuals had achieved a 4 -fold titer reduction, and by 3 -months post-treatment this had increased to $91 \%$. At 1 -month post- treatment, $43 \%$ of those with prior infection and $49 \%$ of syphilis naïve patients had achieved a 4-fold titer reduction (p-value 0.684). At 3 -months the proportions achieving a 4 -fold titer reduction were $88 \%$ among those with previous syphilis infection, and 95\% among those who were syphilis naïve ( $p$ value 0.488 ). After adjusting for baseline titer and HIV status, reaching a 4-fold titer decrease was achieved significantly more quickly among syphilis-naïve individuals, with a hazard ratio of 1.75 (95\% CI:1.11-2.77) compared to those with repeat infection.

Conclusion Compared to past reports, the proportion of syphilis patients achieving serological cure within 3-months was higher in this study. The post-treatment reduction in RPR titer was more pronounced and more rapid among syphilis-naïve individuals.

\section{P205 SEXUAL BEHAVIOURS OF WOMEN LIVING WITH HIV RECEIVING CARE SERVICES AT THE NATIONAL STD/ AIDS CONTROL PROGRAMME SRI LANKA}

D Rajapaksha*, L Rajapaksa. National STD AIDS Control Programme, Colombo, SrLanka

\subsection{6/sextrans-2021-sti.294}

Introduction In Sri Lanka nearly one third of people diagnosed with HIV are women. Little is known about sexual health of HIV infected women in Sri Lanka. This study explored sexual relationships, activities and STI prevalence of women living with HIV (WLHIV) in Sri Lanka.

Objective To describe sexual behaviours of WLHIV receiving care services at the National STD/AIDS control programme Sri Lanka.

Method This is a descriptive cross sectional study among 335 WLHIV in Sri Lanka being followed up at islandwide Anti Retroviral Treatment (ART) centers for at least 1 year

Results Mean age of participants was 43.5 years and age range was from 18 years to 69 years. In total, 98.5\% were taking anti retro viral and had median CD4 count of 641cells/ $\mu$.

Almost all women reported having heterosexual orientation. More than half (53.7\%) were married and $23.9 \%$ were widowed. In total, $67.7 \%$ acquired HIV from their marital or long term partner. Nearly quarter $(23.6 \%)$ mentioned acquisition from a casual partner. $41.2 \%$ stated having a sero concordant partner and $16.1 \%$ were in a sero discordant relationship. 